Proceedings of the 2012 Winter Simulation Conference

C. Laroque, J. Himmelspach, R. Pasupathy, O. Rose, and A.M. Uhrmacher, eds

\title{
USING A SCALABLE SIMULATION MODEL TO EVALUATE THE PERFORMANCE OF PRODUCTION SYSTEM SEGMENTATION IN A COMBINED MRP AND KANBAN SYSTEM
}

\author{
Thomas Felberbauer \\ Klaus Altendorfer \\ Alexander Hübl \\ University of Applied Sciences Upper Austria \\ Wehrgrabengasse 1-3 \\ A-4400 Steyr, AUSTRIA
}

\begin{abstract}
In this paper two different possible machine allocation policies are studied for a production system consisting of MRP and kanban controlled materials. Performance measures are inventory costs, backorder costs and service level. In policy one, the production system is segmented into one segment for MRP planned materials and one for kanban controlled materials. Policy two implements common machine groups for both kinds of materials. A scalable production planning simulation model is applied which is set up by parameterization of the respective database without any model implementation work. For high set-up times and low number of items, we find that whenever utilization of the production system is high, the production system segmentation policy is preferable. However, for medium and low utilization values common machine groups perform best in all scenarios. The scalable simulation model for different kinds of production systems contributes to further research in this field.
\end{abstract}

\section{INTRODUCTION}

Manufacturing system research identifies that the parameterization of production planning and control methods has a big influence on the inventory and tardiness costs as well as on the service level. Published literature shows that the production planning method MRP (material requirements planning) is widely applied and studied (Weeks 1981; Yano 1987; Gong et al. 1994; Elhafsi 2002; Axsäter 2005; Altendorfer and Minner 2011; Hopp and Spearman 2008). Additionally, literature shows that kanban or other pull production control methods can be a viable alternative to the traditional MRP method under certain conditions in the manufacturing system (Spearman et al. 1990; Gstettner and Kuhn 1996; Huang et al. 1998; Mukhopadhyay and Shanker 2005; Takahashi and Myreshka 2005; Jodlbauer and Huber 2008). Such conditions are that the variance in processing time of a production lot is not too high, there are not too many different products and that customer demand is rather stable (Chang and Yih 1994; Jodlbauer 2007; Jodlbauer and Huber 2008). The traditional MRP method can, on the contrary, handle any kind of complexity and variability in processing times and customer demand (Chang and Yih 1994, Hopp and Spearman 2008). In addition to the inventory control behavior, one advantage of kanban in comparison to MRP is that it incurs less planning effort since it is a self organizing system (Ohno 1988, Jodlbauer 2007). Based on these different characteristics which kanban and MRP have, companies in industry sometimes apply both methods on the same shop floor for different materials. Literature is available on the comparison of MRP and kanban for different manufacturing system structures (Jodlbauer and Huber 2008, Huang et al. 1998) and even though there is also literature on the combination of kanban (or pull methods) and MRP (or push methods), e.g. Deleersynder et al. (1992), Berkley (1992), Chang and Yih (1994) and de Smet and Gelders (1998), no studies on the influence of mixing kanban and MRP materials on the same 


\section{Felberbauer, Altendorfer, and Hübl}

manufacturing machines has been found. Motivated by previous empirical research, in this paper a production system is studied with some materials being produced to stock and others being produced to order. In detail the practically relevant problem is how to combine kanban materials (which are produced to stock) and MRP materials (which are produced to order) in one production system. We compare two different possible machine allocation policies where in policy one, the production system is segmented into one segment for MRP planned materials and one for kanban controlled materials. Policy two implements common machine groups for both kinds of materials. For the shop floor organization policy two means that both kanban and MRP production orders are mixed in front of the machines and therefore some additional dispatching effort is needed to identify which order to take. In detail for this policy we apply the earliest due date policy while kanban orders get an artificial due date. In policy one, the shop floor is separated into an MRP and a kanban stream. Thereby no order can switch between the two segments. Performance measures evaluated are inventory costs, backorder costs and service level whereby a major attribute modeled is the setup time when switching between materials. Concerning the performance measurement for kanban and MRP either analytical or simulation models could be applied. Analytical models, as for example applied in the literature stream on planned lead time optimization based on Weeks (1981) and Yano (1987), usually have the advantage that optimal solutions can be identified with respect to certain assumptions. However, their disadvantage is the simple structure of manufacturing systems these models have to assume. On the contrary, simulation studies have the advantage that more complex production system structures can be analyzed, however no optimal solution can be found. In this paper the simulation method is applied where the scalable simulation model which is presented in Hübl et al. (2011) is adapted for this study. This model has the advantage that different manufacturing system structures, including the segmented and common machine policies, can be modeled just by specification of a database.

We examine a flow shop structure inspired by different production companies operating in the automotive sector. The production planning and control methods for the materials are MRP as well as kanban. Half of the finished goods (items) are MRP planned and have an order amount variation coefficient of 0.5. The second half of the items are kanban controlled and have an order amount variation coefficient of 0.25 . The production system has three production stages (production, assembling, and packaging). The research question is how to set the machine allocation policy regarding different numbers of items and materials, different mean order amounts and different demand situations.

\section{MODEL}

The core concept of the scalable simulation model is presented in Hübl et al. (2011) which shows that it is based on a database. The simulation model is parameterized by this database. Thereby it is possible to define different simulation scenarios without any adaption of the simulation model. The relational database model is designed according to the relevant simulation data of a small and medium sized enterprise. Generally the simulation model imports the data from the database in an initial phase. On the one hand the data is used at the startup of the simulation model to replicate the single simulation modules and thereby creating the production system structure. On the other hand the data is used to initialize the random number generators for processing, setup and repair times as well as to parameterize the production planning. Basically, the database distinguishes between master data and transaction data. The master data defines the structure of the production system and consist of:

- Bill of Material (BOM): defining the relationship between parent and child item(s)

- routings: definition of the machine groups and their machines including the capacities

- production planning parameters for each item

- shift calendar for all skill groups including holidays

- definition of skill groups of the employees including their capacities

The transaction data is characterized by distributions, which are used for generating the data. The distribution parameters are defined in tables of the database. A distribution is implemented for processing time, 


\section{Felberbauer, Altendorfer, and Hübl}

set up time, mean time to repair and mean time between failure, customer demand, customer required lead time and replenishment lead time. The simulation time (model run time) is also customized in the database.

The different modules of the scalable simulation model itself are programmed in Anylogic 6.7.1. The basic idea is to replicate the necessary machinery or worker (resources) according to the master data. Therefore, in the initialization of the simulation model, the model is parameterized by an interface to the database according to master data. The simulation model consists of five modules:

- Customer

- Production Planning

- Material Release

- Resources (Machinery, Personnel)

- Analysis

\subsection{Customer}

The module customer is responsible for the generation of customer orders. Therefore, the distribution of customer demand, indicating the pieces needed from a certain final product (item) each period, and the distribution of the customer required lead time, where the relationship between time when the order is stated and the due date, are defined. An alternative is to generate a real customer order list and use it as simulation input. It is possible to model different trends in the demand including seasonality, different product mix combinations and different customer required lead times. If the due date of a customer order is reached, then this module delivers the available items to the customer.

\subsection{Production Planning}

The module production planning uses the master data to create production orders. A hierarchical planning approach according to the MRP II (manufacturing resource planning) concept is applied, whereby the two hierarchical levels long-term and mid-term planning are implemented in the production planning module. Short-term planning is implemented in the resources.

The MPS (master production schedule) is used for long term planning, where the production program is calculated based on forecast data and customer orders. Two different MPS strategies are implemented. In method one, each period the forecast and the customer orders are compared and the larger quantity results in the final production program. In method two, both forecast and customer orders are compared by cumulating them over time. The larger value on the cumulative basis is used for the final production program.

MRP, kanban and a reorder policy are implemented as production planning and control strategies. In the master data for each material, the used planning method, including its parameters, is defined. The MRP parameters are safety stock, planned lead time and lot sizing policy. Quantity of the kanban boxes and the size of one kanban box are the parameters for kanban items. Reorder point and reorder quantity are the two parameters for materials which are controlled by a reorder policy. This module allows analyzing differences in the MPS, production planning strategies and lot sizing policies.

\subsection{Material Release}

This module is responsible to release the necessary materials from stock to produce the product in the right quantity indicated in the production order. If the necessary materials are available then they are released. If one or more materials are out of stock, this production order has to wait until the materials are available. 


\section{Felberbauer, Altendorfer, and Hübl}

\section{$2.4 \quad$ Resources}

The module resources controls the material flow and is responsible for the assignment of personnel. Both machinery and personnel resources are available. Personnel are assigned according to a qualification matrix defined in the master data. Moreover, the master data defines which machine is allocated to a machine group. The working schedules with different shifts defined in the master data are valid for machinery and personnel resources.

Distributions for processing times, set up times, mean time to repair and mean time between failures are implemented in the machinery resources. Different dispatching rules are available, representing the short term level of the hierarchical planning approach. Inventories are only available for production steps which have an own low level code. After each production step, the routing is checked and material is sent either to the next production step or to inventory.

\subsection{Analysis}

The module analysis is responsible for the calculation of the key performance indicators. Service level, average tardiness, average lateness of production orders, average raw material inventory, average WIP, average FGI, average production lead time, average utilization of machine groups (and machines) and average throughput are measured. The calculation is presented in Hübl et al. (2011) in detail.

\section{PROBLEM DESCRIPTION}

This section explains, the flow shop structure, the market scenarios as well as the bill of material and routing information used in the three different simulation experiments conducted in this study. The overall production system structure is similar to that of many automotive suppliers; however, it is just a very streamlined version of such systems which clearly restricts the findings in this study. The streamlined structure, including market structure, the bill of materials and the planning methods, has been created based on project knowledge from past applied research in this industry. Based on the generic simulation model, the same study can be conducted using real company data to fill the database whereby such data is available in all commonly used ERP (enterprise resource planning) systems and/or can be extracted also from MES (manufacturing execution system) systems.

\subsection{Flow Shop Structure}

Figure 2 visualizes the flow shop considered in this paper. The flow shop consists of six machines (M1M6), which are assigned technologically to three machine groups. The three machine groups are production, assembling and packaging. Two machines are allocated to each machine group. The machines in one machine group are identical, so it is possible to produce all products with the same technological request on both machines within the machine groups.

\subsection{Market Scenarios}

In this paper three different scenarios are considered and discussed. The scenarios differ in the number of items and the mean order amount. In the first scenario (S1) a production system with four items, four production materials and two raw materials is analyzed (four-item-high-lotsize-scenario). In scenario two (S2) the same structure with a reduced order amount (four-item-low-lotsize-scenario) is considered. Thereby in scenario two the set up times become significant. In the third scenario (S3), the amount of products is increased by the factor of ten (forty items, forty production materials and twenty raw materials) while simultaneously the demand per month is divided by the same factor to fix the production system utilization on a similar level as in S1 and S2 (forty-item-scenario). In comparing S1, S2 and S3, it is investigated if the effects of different machine allocation policies are the same for the four- and forty-item scenarios. The benefit of the simulation model structure according to Hübl et al. (2011) is to model these 


\section{Felberbauer, Altendorfer, and Hübl}

different scenarios just by a new specification of the database without any simulation model adaption effort.

In Table 1 the demands for the three scenarios are visualized. The customer orders (c.o.) per month in S1 are 3,000 parts for product 10 and 4,500 parts per month for product 11 . The order amount (o.a.) in the simulation model is lognormal distributed with a variation coefficient of 0.5 for the MRP planned materials and 0.25 for the kanban controlled materials. The customer required lead time (crl-time) is lognormal distributed too, with a mean value of ten and a standard deviation of 1.4.

The difference between S1 and S2 is that the mean and the standard deviation of the order amount is reduced to a tenth.

In S3 the variation coefficients for the order amounts and the customer required lead time are the same but the customer orders per month are a tenth of S1. Additionally, the average amount of a customer order is reduced by half to still reach an appropriate service level at a utilization of $85 \%$. This effect can be described due to the increasing set up times arising through the new product variety.

Table 1: Demand situation for scenario one, two and three.

\begin{tabular}{|c|c|c|c|c|c|c|c|c|c|c|c|c|c|}
\hline \multicolumn{3}{|c|}{ Item number } & \multicolumn{3}{|c|}{$\mu$ order amount } & \multicolumn{3}{|c|}{$\begin{array}{c}\sigma \text { order amount } \\
{[\text { pcs.] }}\end{array}$} & \multicolumn{3}{|c|}{$\begin{array}{l}\text { c. o. per month } \\
\text { [pcs.] }\end{array}$} & \multirow{2}{*}{$\begin{array}{c}\mu \text { crl-time } \\
\text { [days] }\end{array}$} & \multirow{2}{*}{$\begin{array}{c}\sigma \begin{array}{c}\text { crl-time } \\
\text { [days] }\end{array} \\
\mathrm{S} 1 / \mathrm{S} 2 / \mathrm{S} 3\end{array}$} \\
\hline S1 & $\mathrm{S} 2$ & S3 & $\mathrm{S} 1$ & $\mathrm{~S} 2$ & S3 & S1 & $\mathrm{S} 2$ & S3 & S1 & $\mathrm{S} 2$ & S3 & & \\
\hline 10 & 10 & $\begin{array}{l}1010- \\
10010\end{array}$ & 100 & 10 & 50 & 50 & 5 & 25 & 3000 & 3000 & 300 & 10 & 1.4 \\
\hline 11 & 11 & $\begin{array}{l}\begin{array}{l}1011- \\
10011\end{array} \\
\end{array}$ & 150 & 15 & 75 & 75 & 7.5 & 37.5 & 4500 & 4500 & 450 & 10 & 1.4 \\
\hline 12 & 12 & $\begin{array}{l}1012- \\
10012\end{array}$ & 100 & 10 & 50 & 25 & 2.5 & 12.5 & 3000 & 3000 & 300 & 10 & 1.4 \\
\hline 13 & 13 & $\begin{array}{l}1013- \\
10013 \\
\end{array}$ & 150 & 15 & 75 & 37.5 & 3.75 & 18.75 & 4500 & 4500 & 450 & 10 & 1.4 \\
\hline
\end{tabular}

\subsection{Bill Of Material}

Figure 1 shows the bill of material for the four-item-scenarios and the LLC (low level code). The LLC indicates the lowest level in a BOM that a particular part is ever used (Hopp and Spearman 2008). It starts with the LLC zero where all items (finished goods) are included. The finished goods are arranged into two product groups called PG1 and PG2. Two descriptive examples for explaining Figure 1 are created. Item 11 with LLC of zero consist of one piece of product 20 with LLC of one. Material 31 consists of one raw material 100 and two raw materials 110. Parts 12, 13, 21 and 31 are kanban controlled. Material 100 and 110 are purchased parts. In this paper it is assumed that the purchased parts are always available and therefore not part of our consideration.

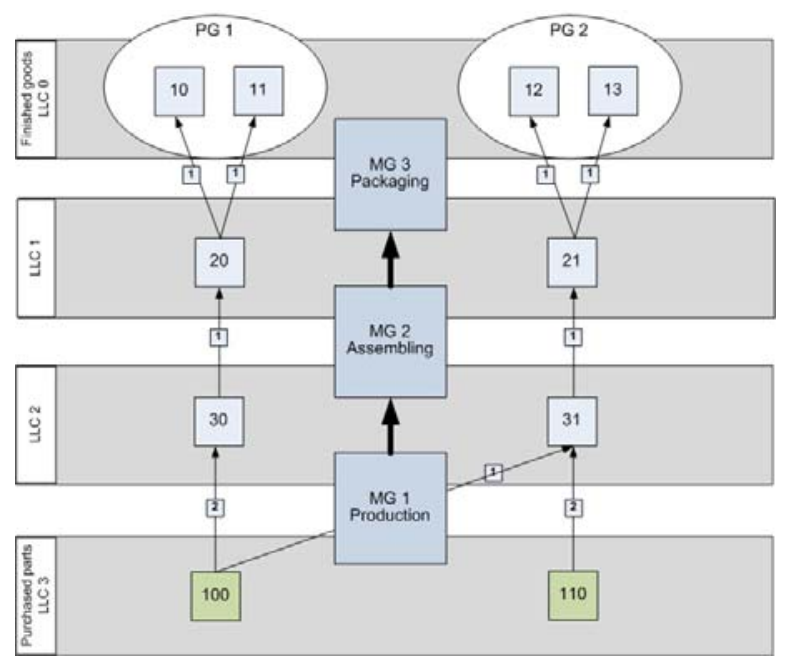

Figure 1: Bill of material and processing structure 


\subsection{Machine Allocation Policies And Routing}

The machine allocation policies differ in the segmentation of the shop floor regarding the two different planning methods. In Figure 2a, machine allocation policy one is visualized. There the production system is segmented into one segment for MRP planned materials and one for kanban controlled materials. Machine allocation policy two (Figure 2b) means that both, kanban and MRP production orders are mixed in front of the machines. Generally the orders are sorted according to the dispatching rule earliest due date (EDD).

a.)

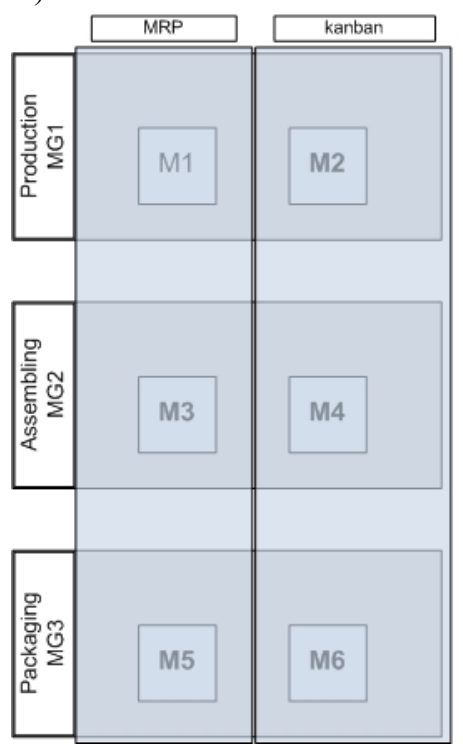

b.)

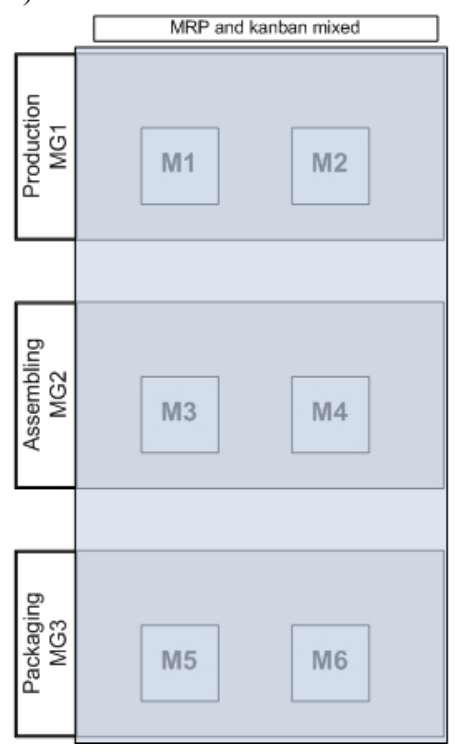

Figure 2: Different machine allocation policies

In the simulation model, lognormal distributed values for processing and set up times are used. It is assumed that the values are the same for all items and materials in all scenarios. Table 2 shows the mean and variance values for processing and set up times. The routing information describes the sequence of workstations passed through by a part.

Table 2: Routing information

\begin{tabular}{|c|c|c|c|}
\hline$\mu$ processing $[\mathrm{min}]$ & $\sigma$ processing $[\mathrm{min}]$ & $\mu$ set up [min] & $\sigma$ set up [min] \\
\hline 4,86 & 2,43 & 6 & 0,15 \\
\hline
\end{tabular}

In the simulation model it is assumed that no set up is needed if orders of the same material are processed sequentially. The same BOM, routing, and planning structure is used for the forty-item-scenario whereby the structure is mirrored tenfold with item $1010,2010, \ldots, 100010 ; 1011,2011, \ldots, 10011$; with their respective materials 1020, 2020,.., 100020; and so on.

\subsection{MEP and Kanban Logic}

MRP and kanban are two production planning and control methods widely applied in industry, however, based on different paradigms. MRP is a push oriented method mainly calculating material requirements based on customer orders (or forecasts) with respect to the BOM. The production order size is identified applying a lot-sizing policy. The planned start and end dates are calculated based on demand occurrences and planned lead times (see Yano (1987) and Hopp and Spearman (2008) for a definition). Therefore MRP can either be applied to MTO or to MTS production systems. In detail, the input data for the MRPrun are the $\mathrm{BOM}$, the on-hand inventory, the scheduled receipts (of orders already running through the 
production system) and the gross requirements of final products from the master production schedule (MPS). For additional information on hierarchical production planning including the calculation of the MPS see Hopp and Spearman (2008). The MRP approach follows a strict calculation scheme (see also Hopp and Spearman (2008)) where the four steps: netting, lot sizing, offsetting and BOM explosion are calculated for each material. The minimum information provided by the production orders generated in the MRP calculation are the material number, the lot size, the start period and the end period of the order. The basic parameters of MRP, also modeled in the current study, are safety stock, lot sizing policy and planned lead time.

A pull alternative to MRP is kanban, which is a pure production control method where production orders are triggered by withdrawal of materials from the kanban boxes. Whenever a box is emptied, a new order for the respective material is issued in the kanban method (see also Ohno (1988) and Hopp and Spearman (2008)). Therefore production is always triggered by demand, either of items (final products) or of production materials. It is a pure MTS method since no information on the future customer demand is processed. The basic parameters of a kanban system, which are also modeled in the current study, are the amount of kanban cards and the size of the kanban boxes (this is equivalent to the lot size in MRP) for each kanban controlled material.

\subsection{Planning Method Parameterization}

In preliminary studies for the three scenarios, the parameters for the two planning methods MRP and kanban and the respective demand settings have been determined to reach a service level of $95 \%$ with a production system utilization of $85 \%$. Table 3 and Table 4 show the different parameters of the planning methods. For the calculation of the kanban lot size and the number of kanbans see also Hopp and Spearman (2008). The MRP lot sizing policy applied is fixed order period (FOP).

Table 3: Planning method parameterization four-item scenarios.

\begin{tabular}{|c|c|c|c|c|c|c|}
\hline Material & Planning type & Safety stock & Planned lead time & FOP Periods & \# kanbans & kanban size \\
\hline 10 & MRP & 200 & 5 & 1 & - & - \\
\hline 11 & MRP & 300 & 5 & 1 & - & - \\
\hline 12 & kanban & - & - & - & 3 & 100 \\
\hline 13 & kanban & - & - & - & 3 & 150 \\
\hline 20 & MRP & 200 & 5 & 1 & - & - \\
\hline 21 & kanban & - & - & - & 4 & 150 \\
\hline 30 & MRP & 300 & 5 & 1 & - & - \\
\hline 31 & kanban & - & - & - & 4 & 15 \\
\hline
\end{tabular}

Table 4: Planning method parameterization forty-item scenario.

\begin{tabular}{|c|c|c|c|c|c|c|}
\hline Material & Planning type & Safety stock & Planned lead time & FOP Periods & \# kanbans & kanban size \\
\hline 10 & MRP & 50 & 5 & 1 & - & - \\
\hline 11 & MRP & 75 & 5 & 1 & - & - \\
\hline 12 & kanban & - & - & - & 3 & 50 \\
\hline 13 & kanban & - & - & - & 3 & 75 \\
\hline 20 & MRP & 50 & 5 & 1 & - & - \\
\hline 21 & kanban & - & - & - & 3 & 75 \\
\hline 30 & MRP & 75 & 5 & 1 & - & - \\
\hline 31 & kanban & - & - & - & 3 & 75 \\
\hline
\end{tabular}




\section{RESULTS}

\subsection{Experiment Design}

In the three scenarios tested, the customer demand per month is varied by changing the parameter lambda (throughput factor) to investigate a utilization range between 50\% and 98\% in twenty iterations. In S1 we analyze a production system with four items, four materials and two raw materials (four-item-highlotsize-scenario). In S2, the same structure with a reduced order amount (four-item-low-lotsize-scenario) is considered. In S3, the amount of products is increased by the factor of ten (forty items, forty materials and twenty raw materials) while simultaneously the demand per month is divided by the same factor (forty-item-scenario).

The performance measures are the overall costs separated in inventory and tardiness costs, the service level and the shop floor utilization. The tardiness costs and the service level are provided for MRP and kanban materials separately. Each iteration is evaluated with the mean value of the overall costs. The tardiness costs are corrected at the end of the simulation run by adding up hypothetic costs for all customer orders not yet satisfied. The ratio of inventory to tardiness costs per piece is one to twenty. In the experiments, one year with 360 days is analyzed whereby each run is replicated 100 times per iteration.

\subsection{Four-Item-Scenarios}

In Figure 3, the curves for service level (Figure 3a) and overall costs (Figure 3b) for the two different machine allocation policies for S1 are visualized (four-item-high-lotsize-scenario). Both curves are plotted with respect to the throughput-factor lambda, which determines the shop floor utilization. The secondary axis of Figure $3 \mathrm{a}$ shows the service level difference of the two machine allocation policies. The service level curve of the segmented machine allocation policy is slightly better than the one of the not segmented policy. In this scenario, the ratio of set up time in comparison to processing time is very low $(<1 \%$ of the shop floor utilization). The overall costs show at high throughput levels significant differences. In this scenario, especially the tardiness costs of the segmented machine allocation policy are higher than the tardiness costs of the not segmented policy.
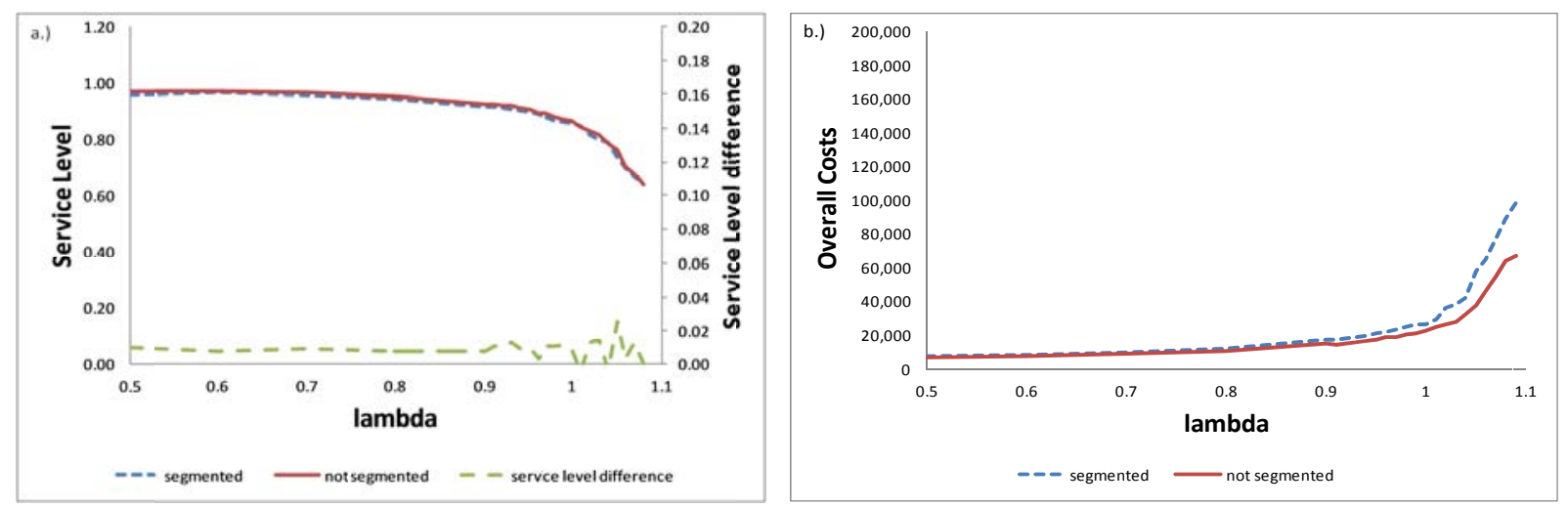

Figure 3: Service level and overall costs for the two machine allocation policies in the four-items-highlotsize-scenario S1

In Figure 4, the curves for service level (Figure 4a) and overall costs (Figure 4b) for the four-item-lowlotsize-scenario (S2) is visualized (higher amount of set ups due to the reduced average order amount). For a high throughput, the segmented machine allocation policy has a significant better service level performance than the non segmented machine allocation policy. This results from the reduced setup effort with the segmented machine allocation policy. According to the service level curve, Figure $4 \mathrm{~b}$ shows that the segmented machine allocation policy has less overall cost for high throughput levels. Note that for low throughput the common machine group policy performs better. 

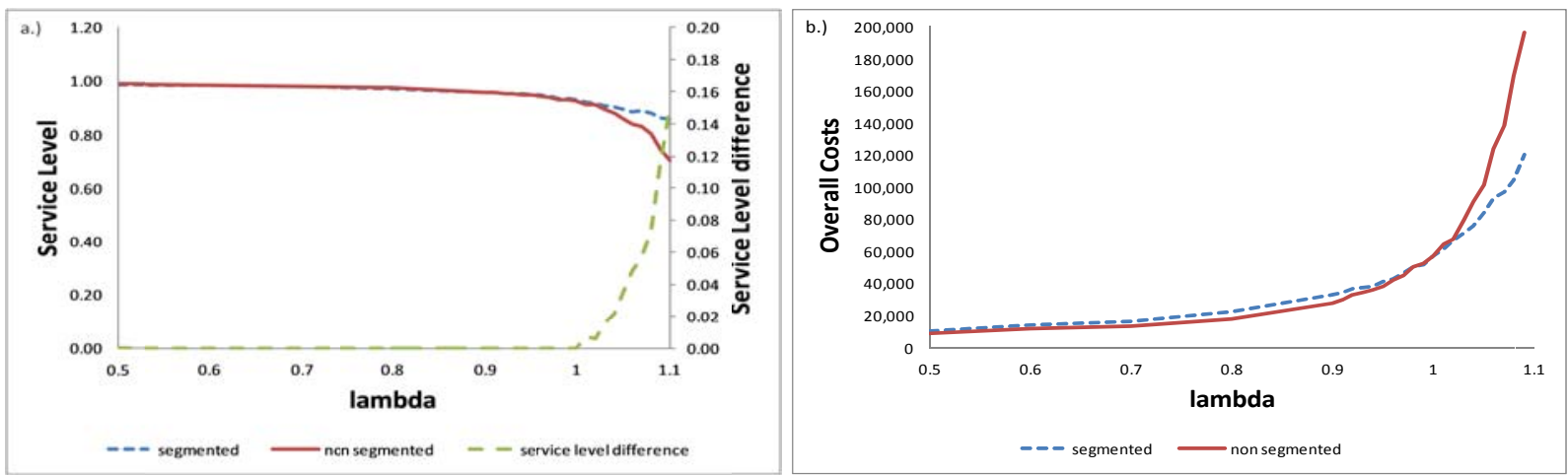

Figure 4: Service level and overall costs for the two machine allocation policies in the four-items-lowlotsize-scenario S2

\subsection{Forty-Item-Scenario}

In Figure 5, the curves of the service level (Figure 5a) and the overall costs (Figure 5b) for the two different machine allocation policies for the forty-items-scenario $\mathrm{S} 3$ are plotted.
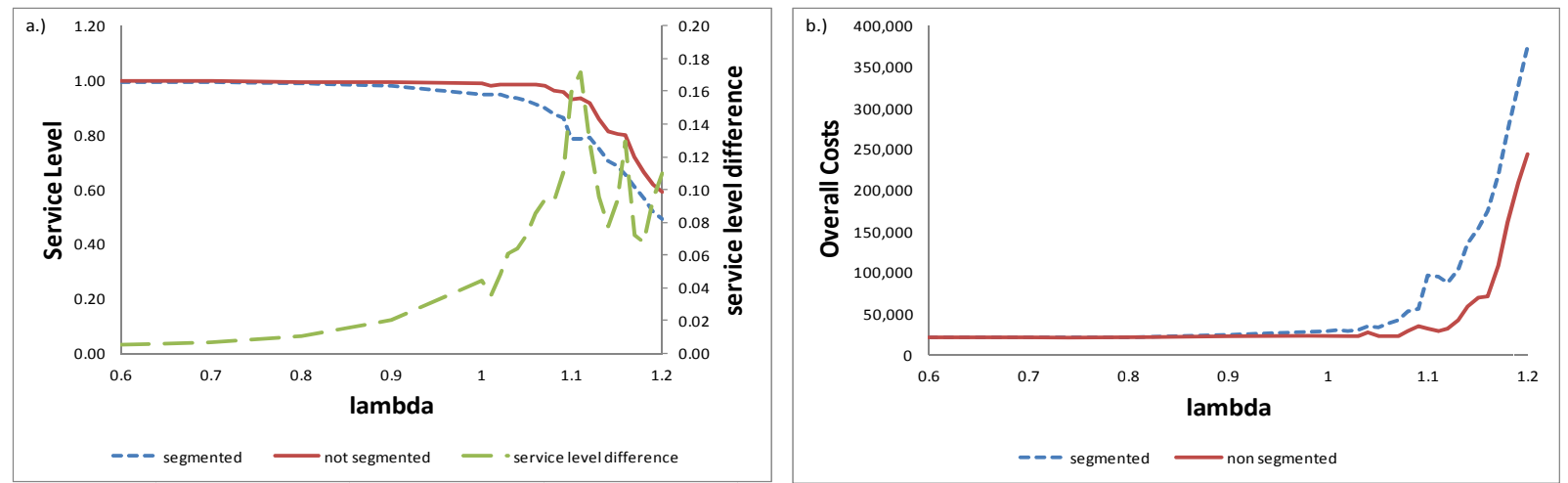

Figure 5: Service level and overall costs for the two machine allocation policies in the forty-itemsscenario S3

Figures $5 \mathrm{a}$ and $5 \mathrm{~b}$ show that there are only slight differences between the two machine allocation policies for a low throughput (lambda). Starting at a lambda of 0.9 (which is approximately equal to a shop floor utilization of $80 \%$ ) the non segmented machine allocation policy performs better than the segmented policy both for the service level and the overall costs. For example, for a lambda value of 1.1 the service level of the non segmented policy is $14 \%$ better than the service level of the segmented machine allocation policy. This better performance is linked to the increasing routing flexibility of the non segmented case which overcomes the advantage of the reduced set up times of the segmented machine allocation policy. Especially with a high number of materials and items, the segmentation policy only restricts the routing but does not yield any performance gain since only few set-up reduction potential exists.

\subsection{MRP And Kanban Performance Comparison}

In Figure 6, the service level (S1a, S2a, and S3a) and tardiness (S1b, S2b and S3b) curves for the three scenarios are compared for the MRP and kanban materials. It is shown that for all three scenarios the kanban controlled materials have a better service level performance. As discussed in section 1, the combination of kanban and MRP materials being processed on the same resources leads to the problem of dispatching two different kinds of orders. In this study, the production orders in the machine groups are sorted according to the earliest due date rule. For MRP-materials the planned due date of the production 
order is the planned start period of the parent item of the next low level code (lower LLC). For the kanban controlled materials the planned due date is modeled as the time of the production order creation, so the kanban controlled materials are generally prioritized. The better performance of kanban in the segmented machine allocation policy shows that for the studied production system with its demand variances, the MTS policy performs better than the MTO policy. When applying the non segmented machine allocation policy, the kanban prioritization influences the MRP materials. The results for S2, where the overall performance of the segmented policy is better, show that the prioritization of kanban materials leads to a significant service level reduction for MRP planned materials. The tardiness figures show no consistent behavior due to simulation results variance at high throughput. These findings have also been tested with a set of different cost und planning parameters in structure S1 whereby the principal results concerning costs and service level stay unchanged but the single numbers clearly differ in this sensitivity analysis.
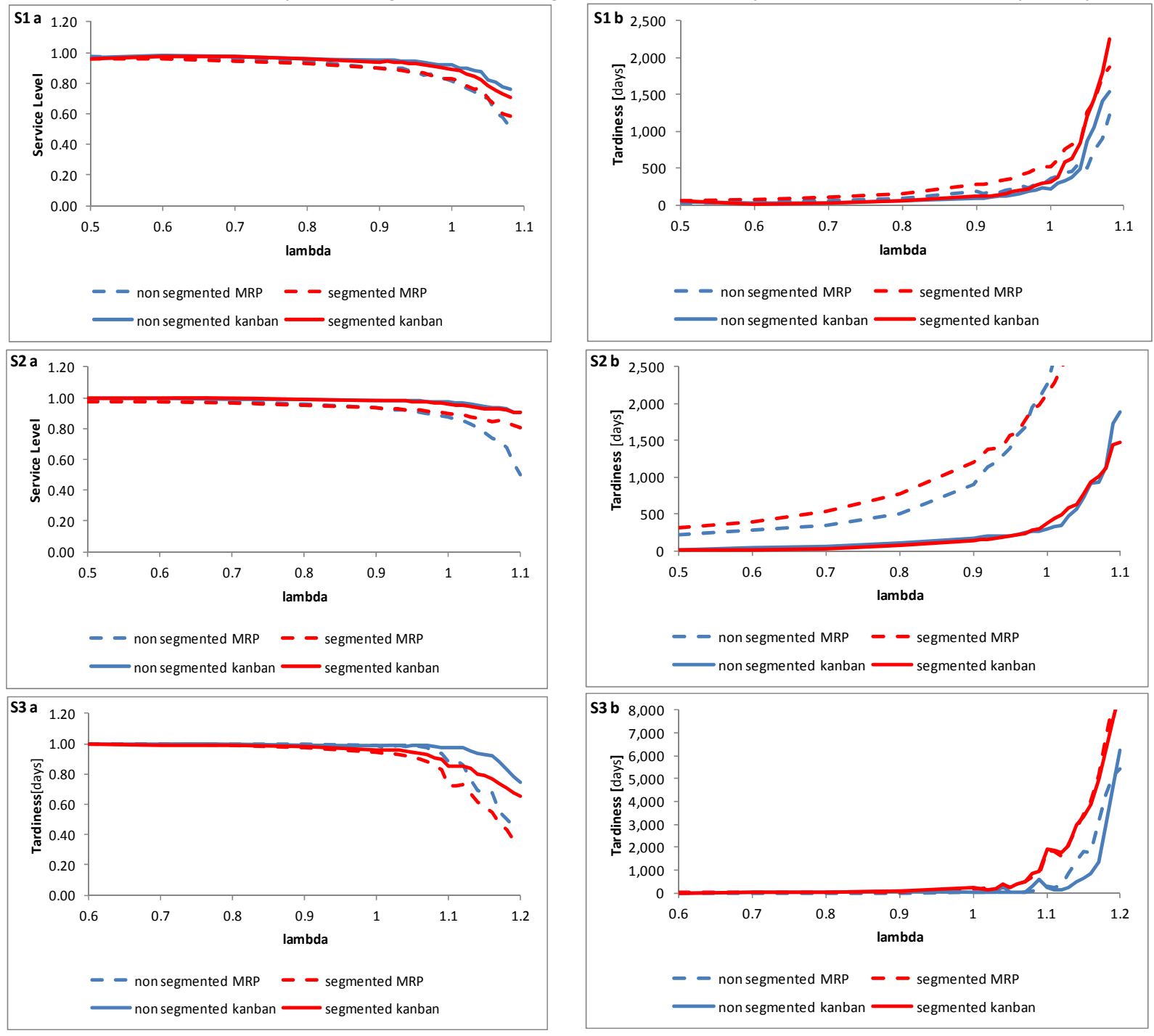

Figure 6: Service level and tardiness of MRP / kanban materials for the three scenarios

\section{CONCLUSION}

The simulation study performed in this paper shows that the flexible simulation model with the database connection is perfectly suited to represent scalable production systems. We find that in a production system with low set up times, the service level performance is for low utilization nearly independent of the 


\section{Felberbauer, Altendorfer, and Hübl}

machine allocation policy applied. However, at high utilization, the increased production system flexibility of not segmenting the production system improves this performance. Especially when comparing the overall costs, the non segmented production system leads in such situations to significantly lower costs than the segmented one. In a scenario with high setup time impact, we find significant cost improvements of the segmented production system in comparison to the non segmented one for high throughput. This cost improvement results from the overall setup time reduction overweighting the flexibility loss of this policy. However, studying the same situation with a higher number of items shows that the setup time gain diminishes and the flexibility loss of the segmentation leads to higher costs in all throughput situations. Additionally, the service level and tardiness performance of MRP and kanban planned materials in the segmented and non segmented production system are compared. We find a service level reduction of MRP parts in comparison to kanban parts in the non segmented production systems. This leads to a further research need to identify how to dispatch MRP and kanban materials if they both seize the same machines. The contribution of this paper is further limited by the specific scenarios studied. Therefore, further research is required to investigate the detected behavior in a broader range of production system structures.

\section{REFERENCES}

Altendorfer, K. and Minner, S. 2011. "Simultaneous optimization of capacity and planned lead time in a two-stage production system with different customer due dates." European Journal of Operational Research 213: 134-146.

Axsäter, S. 2005. "Planning order releases for an assembly system with random operation times." $O R$ Spectrum 27: 459-470.

Berkley, B. J. 1992. "A review of the kanban production control research literature." Production and Operations Management 4: 393-411.

Chang, T. M. and Yih, Y. 1994. "Generic kanban systems for dynamic environments." International Journal of Production Research 32: 889-902.

Deleersynder, J.-L., Hodgson, T. J., King, R. E., O‘Grady, P. J., and Savva, A. 1992. "Integrating Kanban type pull systems and MRP type push systems: insights from a markovian model." IIE Transactions 24: 43-56.

Elhafsi, M. 2002. "Optimal leadtimes planning in serial production systems with earliness and tardiness costs." IIE Transactions 34: 233-243.

Gong, L., Kok, T. de, and Ding, J. 1994. "Optimal Leadtimes Planning in a Serial Production System." Management Science 40: 629-632.

Gstettner, S. and Kuhn, H. 1996. "Analysis of production control systems kanban and CONWIP." International Journal of Production Research 34: 3253-3273.

Hopp, W. J. and Spearman, M. L. 2008. Factory Physics. Boston: Mc Graw Hill / Irwin.

Huang, M., Wang, D., and Ip, W. H. 1998. “A simulation and comparative study of the CONWIP, Kanban and MRP production control systems in a cold rolling plant”. Production Planning \& Control 9: 803812.

Hübl, A., Altendorfer, K., Jodlbauer, H., Gansterer, M., and Hartl, R. F. 2011. „Flexible Model for Analyzing Production Systems with Discrete Event Simulation." In Proceedings of the 2011 Winter Simulation Conference. December 11 - 14, 2011, Phoenix, Arizona, U.S.A. ; [including] MASM (Modeling and Analysis for Semiconductor Manufacturing) Conference, IEEE Service Center, Piscataway, NJ, $1559-1570$.

Jodlbauer, H. 2007. Produktionsoptimierung: Wertschaffende sowie kundenorientierte Planung und Steuerung. Wien u.a.: Springer.

Jodlbauer, H. and Huber, A. 2008. "Service-level performance of MRP, Kanban, CONWIP and DBR due to parameter stability and environmental robustness." International Journal of Production Research 46: 2179-2195. 
Mukhopadhyay, S. K. and Shanker, S. 2005. "Kanban implementation at a tyre manufacturing plant: a case study". Production Planning \& Control 16: 488-499.

Ohno, T. 1988. Toyota production system. Beyond large-scale production. Productivity Press, Cambridge, Mass.

Smet, R. de and Gelders, L. 1998. "Using simulation to evaluate the introduction of a Kanban subsystem within an MRP-controlled manufacturing environment." International Journal of Production Economics 56-57: 111-122.

Spearman, M. L., Woodruff, D. L., and Hopp, W. J. 1990. “CONWIP: a pull alternative to kanban”. International Journal of Production Research 28: 879-894.

Takahashi, K. and Myreshka, D. H. 2005. "Comparing CONWIP, synchronized CONWIP, and Kanban in complex supply chains". Proceedings of the Twelfth International Symposium on Inventories. International Journal of Production Economics 93-94: 25-40.

Weeks, J. K. 1981. "Optimizing Planned Lead Times and Delivery Dates”. 21 st Annual Conference Proceeding, American Production and Inventory Society: 177-188.

Yano, C. A. 1987. "Setting Planned Leadtimes in Serial Production Systems with Tardiness Costs". Management Science 33: 95-106.

\section{ACKNOWLEDGMENTS}

This paper was written within the framework of the project "SimGen" (project number 826789) funded by the Austrian Research Promotion Agency (FFG).

\section{AUTHOR BIOGRAPHIES}

THOMAS FELBERBAUER works as a Research Associate in the field of Operations Management at the University of Applied Sciences, Steyr (Austria). His research interests are discrete event simulation and combinatorial optimization. His email address is thomas.felberbauer@fh-steyr.at.

ALEXANDER HÜBL works as a Research Associate in the field of Operations Management at the University of Applied Sciences, Steyr (Austria). His research interests are discrete event simulation and quantitative methods for capacity setting. His email address is alexander.huebl@fh-steyr.at.

KLAUS ALTENDORFER works as a Professor in the field of Operations Management at the University of Applied Sciences, Steyr (Austria). He received his $\mathrm{PhD}$ degree in logistics and operations management with distinction and has professional experience in stochastic inventory models and production planning and control. His e-mail address is klaus.altendorfer@fh-steyr.at. 